\title{
The Weiss Score and Beyond-Histopathology for Adrenocortical Carcinoma
}

\author{
Mauro Papotti • Rossella Libè • Eleonora Duregon • \\ Marco Volante $\cdot$ Jerome Bertherat $\cdot$ Frederique Tissier
}

Published online: 14 October 2011

(C) Springer Science+Business Media, LLC 2011

\begin{abstract}
The pathological diagnosis of adrenocortical carcinoma (ACC) is still challenging for its rarity and the presence of special variants (pediatric, oncocytic, myxoid, and sarcomatoid). It is based on the recognition at light microscopy of at least three among nine morphological parameters, according to the Weiss scoring system, which has been introduced 27 years ago and nowadays is the most widely employed. Nevertheless, the diagnostic performance of this system is very high but does not reach a sensitivity and specificity of $100 \%$, its diagnostic applicability is potentially low among non-expert pathologists, and a group of borderline cases with only one or two criteria exist of uncertain behavior. Moreover, it is scarcely reproducible in the ACC morphological variants. In fact, specifically for the pure oncocytic neoplasms that seem to have a better
\end{abstract}

M. Papotti $\cdot$ E. Duregon $\cdot$ M. Volante $(\triangle)$

Department of Clinical and Biological Sciences,

University of Turin at San Luigi Hospital,

regione Gonzole 10,

10043 Orbassano, Turin, Italy

e-mail: marco.volante@unito.it

R. Libè · J. Bertherat

AP-HP, Service des maladies endocriniennes et métaboliques,

Hôpital Cochin, Faculté de Médecine Paris Descartes,

Université Paris Descartes,

Paris, France

R. Libè $\cdot$ J. Bertherat $\cdot$ F. Tissier

INSERM U1016 et CNRS UMR8104, Institut Cochin,

Département Endocrinologie Métabolisme et Cancer,

Réseau COMETE,

Paris, France

F. Tissier

AP-HP, Service d'Anatomie Pathologique, Hôpital Cochin, Faculté de Médecine Paris Descartes, Université Paris Descartes, Paris, France prognosis in comparison to the conventional ACCs, a modified system (the Lin-Weiss-Bisceglia) has been proposed. With the aim to simplify the ACC diagnosis, 2 years ago, the "reticulin" diagnostic algorithm has been proposed, based on the observation that the tumoral reticulin framework (highlighted by reticulin silver-based histochemical staining) is consistently disrupted in malignant cases but only in a small subset of benign cases. Following this algorithm, in the presence of reticulin alterations, malignancy is further defined through the identification of at least one of the following parameters: necrosis, high mitotic rate, and venous invasion. As a complement to the morphological approach, some immunohistochemical markers (such as steroidogenic factor 1) have been proposed as diagnostic and prognostic adjuncts but still lack wide clinical validation.

Keywords Adrenocortical carcinoma. Weiss scoring system $\cdot$ Diagnostic algorithm $\cdot$ Morphological variants

\section{Introduction}

Adrenocortical cancer (ACC) is a rare and aggressive disease with an incidence of approximately one case per million. The presence of distant metastases at the time of diagnosis is relatively common, and its differential diagnosis in this clinical situation is mainly related to the exclusion of other malignant neoplasms metastatic to the adrenal, especially in inoperable cases [12]. However, due to the growing incidence of adrenal nodules discovered incidentally during radiological procedures for unrelated clinical conditions, the proportion of cases confined to the adrenal is increasing, together with the diagnostic difficulties in differentiating benign from malignant adrenocortical 
neoplasms [14]. In fact, at variance with other endocrine tumors (i.e., follicular tumors of the thyroid), the pathological diagnosis of "carcinoma" does not rely on clear-cut morphological parameters but mostly on a combination of multiple features suggestive, but not pathognomonic per se, of malignancy [22]. Therefore, in the last decades, variable combinations of such parameters in different scoring systems have been proposed in the literature [21, 43] being the scoring method proposed by Weiss in 1984 [48] with subsequent modifications [49] and revisions [2] by far the most widely employed.

\section{The Weiss Scoring System}

The Weiss scoring system is based on the recognition at light microscopy of nine morphological parameters: three of them are related to tumor structure, namely presence of eosinophilic ("dark") cytoplasm in more than $75 \%$ of tumor cells, of a "patternless" diffuse architecture, and of necrosis; three others are related to cytological features, namely presence of nuclear atypia, of mitotic index above 5 per 50 high-power fields, and of atypical mitoses; the remaining three are related to invasive tumor properties, including sinusoidal, venous, and capsular invasion (Table 1). A diagnosis of malignancy is achieved if at least three parameters are identified. Although the recognition of each of these parameters is based on well-defined and stringent morphological criteria [23], in the general practice, the diagnostic applicability of the Weiss system is not always easy since some of these features (diffuse growth, necrosis,

Table 1 The Weiss system

\begin{tabular}{lll}
\hline Histological criteria & \multicolumn{2}{l}{ Weight of criteria } \\
\cline { 2 - 3 } & 0 & 1 \\
\hline Nuclear grade $^{\mathrm{a}}$ & 1 and 2 & 3 and 4 \\
Mitoses & $\leq 5$ for 50 fields $\times 400$ & $\geq 6$ for 50 fields $\times 400$ \\
Atypical mitoses & No & Yes \\
Clear cells & $>25 \%$ & $\leq 25 \%$ \\
Diffuse architecture & $\leq 33 \%$ surface & $>33 \%$ surface \\
Confluent necrosis & No & Yes \\
Venous invasion & No & Yes \\
Sinusoidal invasion & No & Yes \\
Capsular infiltration & No & Yes \\
\hline
\end{tabular}

The presence of three or more criteria highly correlates with malignancy [46]

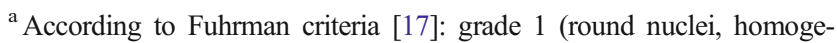
nous, small size, no nucleoli), grade 2 (nuclei slightly irregular, more voluminous, conspicuous nucleoli at $\times 400$ ), grade 3 (irregular nuclei, voluminous nucleoli at $\times 100$ ), grade 4 (idem grade 3 with monstrous cells with very irregular nuclei) sinusoidal, vascular and capsular invasion, nuclear atypia) are subjective (in terms of presence and/or quantification) or biased by the adequacy of tumor sampling [46]. Moreover, the diagnostic performance is very high but does not reach a sensitivity and specificity of $100 \%$. In order to simplify the diagnostic approach and improve the diagnostic performance of the Weiss system, some modifications have been proposed in the past, including a statistically modified system based on the most reliable criteria [2] that take into account mitotic rate and dark cytoplasm (both scored 2), and abnormal mitoses, necrosis, and capsular invasion (scored 1 each), with an overall cutoff score for malignancy set at 3 . However, although such modifications intended to implement the accuracy of ACC pathological diagnosis, they have been validated only in one further study [43] and did not replace the classical Weiss system in the common clinical practice.

\section{Diagnostic Reproducibility}

As discussed above, not all diagnostic features considered in the Weiss scoring system are easy to recognize and apply, and therefore, a major limitation in the diagnostic applicability of the Weiss score is related to its potentially low reproducibility. Few studies aimed at investigating the inter-observer agreement among pathologists. In the revisitation by Aubert and coworkers [2], inter-observer agreement for the total Weiss score was excellent $(r=0.94)$ among experts, but this is apparently not so straightforward in the common practice.

A program that aimed at harmonizing and improving the performance of the pathological diagnosis of adrenal cortical tumors in France, through the National INCa-COMETE (Institut National du Cancer-COrtico-MEdullo Tumeurs Endocrines) Network, was initiated. Pathologists from all reference centers of the National INCa-COMETE Network analyzed 50 adrenal cortical tumors, using a web-based virtual slide system, in a blind design allowing to determine the intra- and inter-observer reproducibility of the Weiss scoring system before and after a coaching meeting was organized to harmonize and improve analyses (USCAP Washington 2010, online communication and paper in preparation).

\section{The Problem of Borderline Cases}

In the majority of cases, the differential diagnosis between adrenocortical adenoma and carcinoma is easy to assess [22]. The vast majority of adenomas consistently lack all Weiss parameters, whereas most cases of adrenocortical carcinoma (62\% in a series of 201 cases from Turin; Table 2) have a Weiss score of 6 or higher, thus being easily recognized as malignant. However, in some cases (approximately up to 
Table 2 Descriptive clinical and pathological features in an Italian cohort of adrenocortical carcinomas

\begin{tabular}{ll}
\hline No. of cases & 201 \\
F/M & $118 / 83$ \\
Mean age (range) & $47(3-85)$ \\
Functional status & (known in 157 cases) \\
Not functioning & 76 \\
Cortisol & 52 \\
Cortisol+androgens & 10 \\
Androgens/estrogens & $6 / 2$ \\
Aldosterone & 6 \\
"Hypertension" & 5 \\
Follow-up & $(\mathrm{known}$ in 188 cases $)$ \\
NED/DOC & 69 \\
AWD & 47 \\
DOD & 72 \\
Location left/right adrenal & $\left(\mathrm{known}\right.$ in 179 cases) $102 / 75^{\mathrm{a}}$ \\
Mean size, cm (range) & $11.3(1.6-28)$ \\
Mean weight, g (range) & $480(8-4,000)$ \\
Mean Weiss score & $6.25^{\mathrm{b}}$ \\
Weiss score 3-5/6-9 & $71 / 118^{\mathrm{b}}$ \\
Pediatric & 1 \\
Myxoid variant & 20 \\
Oncocytic variant & 22 \\
Sarcomatoid variant & 0 \\
\hline
\end{tabular}

$N E D$ no evidence of disease, $A W D$ alive with disease, $D O C$ died of unrelated causes, $D O D$ died of disease

${ }^{\text {a }}$ Two bilateral tumors

${ }^{\mathrm{b}}$ Not applicable in 12 cases because of metastases, biopsies, postchemotherapy, or radiotherapy

$10 \%$ of adrenal cancer series in the Authors' personal experience), only one or two Weiss parameters are recognized, with a final score not sufficient for a diagnosis of malignancy, but suggestive of a malignant potential, although uncertain. These cases are worrisome from both pathological and clinical standpoints since these, on the one hand, underline the need of a more unequivocal pathological classification and, on the other, pose questions on their appropriate clinical management and follow-up. In most of such "borderline" cases, the commonly recognized Weiss parameters include one or two of the following: nuclear atypia, eosinophilic cytoplasm, diffuse growth, or sinusoidal invasion. These are parameters that generally have the lowest specificity when correlated to malignant behavior; by contrast, conventional malignancy-related parameters, such as high mitotic index, atypical mitoses, necrosis, vascular and capsular invasion, are usually not occurring alone, but are rather combined with other parameters, thus easily determining a high Weiss scores [46]. A possible exception is represented by early incidentally detected ACCs that may have small size and, although in the presence of mitotic activity, might lack signs of invasion that usually develop later during tumor progression. Based on the above comments, a diagnosis of "borderline" or "uncertain malignant potential" tumor should be rendered only after extensive tumor sampling and evaluation of an adequate number of histological sections.

\section{Adrenocortical Carcinoma Variants}

\section{Pediatric Tumors}

Pediatric adrenocortical tumors are even more rare than their adult counterpart and, although the majority of cases show morphological features related to malignancy, usually present a less aggressive clinical behavior [23]. Very few studies have addressed this issue in a consistent number of cases, being the AFIP series with 83 pediatric tumors the largest one [50]. In this study, among the classical criteria considered in the Weiss system, only confluent necrosis, capsular or vascular invasion, presence of atypical mitotic figures, and a mitotic count $>15$ per 20 high-power fields were significantly related to poor prognosis. Conversely, some others, such as eosinophilic cytoplasm, diffuse architecture, or sinusoidal invasion, were apparently less relevant. Four additional parameters also had a relevant impact on prognosis, including tumor weight $>400 \mathrm{~g}$, tumor size $>10.5 \mathrm{~cm}$, vena cava invasion, and periadrenal tissue infiltration.

\section{Oncocytic Tumors}

This term refers to a subset of adrenocortical tumors with a predominant component of large, deeply eosinophilic, mitochondrion-rich cells. As originally stated by Bisceglia and coworkers [4], the diagnosis of malignancy in oncocytic tumors is difficult using the classical Weiss scoring system since at least three parameters (eosinophilic cytoplasm, high nuclear grade, and diffuse architecture) are intrinsically present in this tumor type, irrespective of the biological and clinical behavior. Therefore, the cutoff values validated for conventional adrenocortical carcinoma may lead to an overdiagnosis of malignancy in this special group. Modified scoring systems which separately analyze "major" (mitotic index, atypical mitoses, and venous invasion) and "minor" (necrosis, capsular and sinusoidal invasion, size $>10 \mathrm{~cm}$, and weight $>200 \mathrm{~g}$ ) criteria have therefore been proposed to define three groups of tumors (benign, borderline, and malignant) that possess distinct clinical behavior [52].

\section{Myxoid Tumors}

Focal extracellular deposits of myxoid material, highlighted by positive Alcian-Blue staining, are not uncommon in 
adrenocortical benign and malignant neoplasm, but they may be predominant in a subset of approximately $10 \%$ of ACC [31]. In such cases, especially in biopsy material, a distinction from extraskeletal myxoid chondrosarcoma, chordoma, myxoid carcinomas from the kidney or other sites, myxoid lipomatous, or nerve sheet tumors should be taken into account. Moreover, the distinction between benign and malignant adrenocortical myxoid tumors may be worrisome. In a recent series of 14 cases reported by our group [31], we could observe that most cases were characterized by a trabecular, chordonal, or micro-alveolar growth of small cells with absent or mild nuclear pleomorphism, thus lacking two Weiss parameters (diffuse growth and nuclear atypia). Moreover, the identification of invasive areas might be equivocal due to the presence of abundant myxoid background. Therefore, it is advisable in adrenal tumors with predominant myxoid stroma to suspect malignancy even in tumors with an apparently low grade appearance.

\section{Sarcomatoid Carcinoma}

This adrenocortical carcinoma variant is extremely rare, and to our knowledge, only nine cases have been reported in the literature so far $[3,8,9,10,16,24,30,33,38]$. This tumor type is aggressive, and the recognition of diagnostic features of malignancy is not problematic.

\section{Beyond the Weiss Score}

As also stated above, the diagnostic work-up of adrenocortical tumors is still time-consuming and poorly reproducible. An alternative view to the use of diagnostic scoring systems (the Weiss or others) is the definition of algorithmic approaches based on the recognition of the most relevant pathological features, such as mitotic index, and the exclusion of less sensitive or poorly specific or equivocal features. Following this alternative approach, in 2007, a study suggested to select malignant cases through a diagnostic algorithm based on mitotic count ( $>5 / 50 \mathrm{HPF}$ ), followed by the recognition of other parameters (including nuclear grade, diffuse growth pattern, and tissue reaction) [5]. A comparison with the other known scoring systems indicated that a stepwise procedure was the most specific, while the pathological scores proposed in Weiss and vanSlooten systems were the most sensitive for adrenocortical carcinoma diagnosis.

Two years later, we proposed a diagnostic algorithm based on the observation that the disruption of the reticulin framework (highlighted by reticulin silver-based histochemical staining) is a consistent finding in ACC and is only occasionally encountered in benign (Weiss score $\leq 2$ ) adrenocortical tumors [45]. This histochemical feature was therefore considered as the primary step for the recognition of malignancy. The additional presence of at least one of the malignancy-related criteria conventionally considered in several endocrine tumors (necrosis, mitotic rate $>5 / 50 \mathrm{HPF}$, as in the Weiss system, and venous vessel invasion) raised up to $100 \%$ the sensitivity and specificity of the proposed algorithm for a diagnosis of malignancy in a series of 92 cases. This simplified scheme has the major advantage of reducing the analysis of other parameters such as nuclear atypia, eosinophilic cytoplasm, sinusoidal and capsular invasion, that, although commonly found in malignant lesions, may be of equivocal definition and are sometimes subjective. In addition, it has been validated in our extended and updated (April 2011) Turin series of 201 ACC, but not in external series, yet.

\section{Minimal Requirements for Pathological Reporting}

One of the most relevant issues in ACC diagnosis is the lack of homogeneity and standardization in pathological reporting. Several papers and recommendations highlighted the need of referral centers for ACC diagnosis, but even in centers of excellence, a standardization of the diagnostic procedure and reporting is not uniformly accepted. It is the common opinion of these Authors that a minimal dataset of information should be included in the pathological report of any ACC case (Table 3).

Table 3 Minimal requirements for pathological reporting

Macroscopy (one paraffin inclusion $\times \mathrm{cm}$, with special reference to the capsule/invasive front)

- Integrity of the sample, including tumor surface

- Size (three dimensions) and weight

- Description of the cut surface

- Description of the tumor borders, including presence and integrity of the tumor capsule, adhesion/invasion of adjacent tissues/structures

- Presence of residual adrenal tissue

Microscopy

- Type of scoring system applied (Weiss system to be preferred)

- Description of each individual parameter considered (mandatory to specify the numerical value of mitotic index in 50 high-power fields)

- Status of the resection margins

- Immunoprofile, if performed

- Ki-67 labeling index ${ }^{\mathrm{a}}$

Diagnosis

- Diagnosis, including variants

- pTNM stage (specify which, for example, AJCC/WHO or ENSAT) [13]

${ }^{\text {a }}$ Based on recent literature data and according to the Hôpital Cochin experience, some more immunohistochemical markers may be added but are still not recommended in the daily practice, and include $\mathrm{p} 53$, cyclin $\mathrm{E}$, and beta-catenin 


\section{The Need of a Grading System}

Apart from diagnostic consideration, a critical reappraisal of the most relevant pathological parameters in ACC diagnosis led to the recognition that some of them have a prognostic impact being their expression also correlated to survival. In this respect, a study by Assie and coworkers was reported on 124 metastatic cases [1] and claimed the importance of high mitotic index (and the presence of atypical mitotic figures) as the most relevant factor significantly correlated with clinical aggressiveness and poor survival. This same observation was also confirmed by other studies although with heterogeneous cutoff values $[20,28,45]$ and supports the concept that a grading system based on mitotic count might help in the prognostic stratification of patients [19].

\section{Molecular Markers in the Diagnosis and Prognosis of ACC}

Apart from the prognostic impact of mitotic count already discussed above, none of the pathological parameters commonly used for the definition of malignancy in adrenocortical tumors is associated to a specific clinical behavior. A value of the total Weiss score to predict the clinical outcome has been postulated by some authors [44], but does not reflect our personal experience [45]. Some immunohistochemical markers were shown to be independent predictors of clinical aggressiveness, includingamong the most recent-matrix metalloproteinase type 2 [47], glucose transporter 1 [15], and steroidogenic factor 1 (SF-1) [35]. However, none of them has been validated enough to be considered a novel potential prognostic biomarker in ACC. Therefore, molecular strategies are expected to better depict the molecular pathways responsible for adrenal cancer onset and progression and to identify new markers and possible therapeutic targets.

\section{Ki-67 Proliferation Index}

Ki-67 proliferation index study can bring additional help for establishing malignancy diagnosis (Fig. 1). A proliferation index over 5\% has only been observed in ACC [27], but ACC with low proliferation index can exist, parallel to those observed in adrenocortical adenoma (ACA) [27, 29, 37]. Some papers [29, 39] reported that a high level of Ki67 seems to correlate with a shortness disease survival and maybe useful as a marker of worse prognosis. However, at present for adrenocortical neoplasms, variability in Ki-67 staining procedure and evaluation might be responsible for poor standardization and applicability of this marker as a diagnostic tool, and detailed recommendation is therefore needed. In our opinion, it seems reasonable to recommend
Fig. 1 Adrenocortical carcinoma, morphological and immunophenotypical patterns. Hematoxylin-eosin $(\mathbf{a}, \times 200)$, immunohistochemical staining for SF-1 (b, ×200), Ki-67 (c, $\times 200)$, for p53 $(\mathbf{d}, \times 200)$, cyclin $\mathrm{E}(\mathbf{e}, \times 200)$, and $\beta$-catenin $(\mathbf{f}, \times 200)$
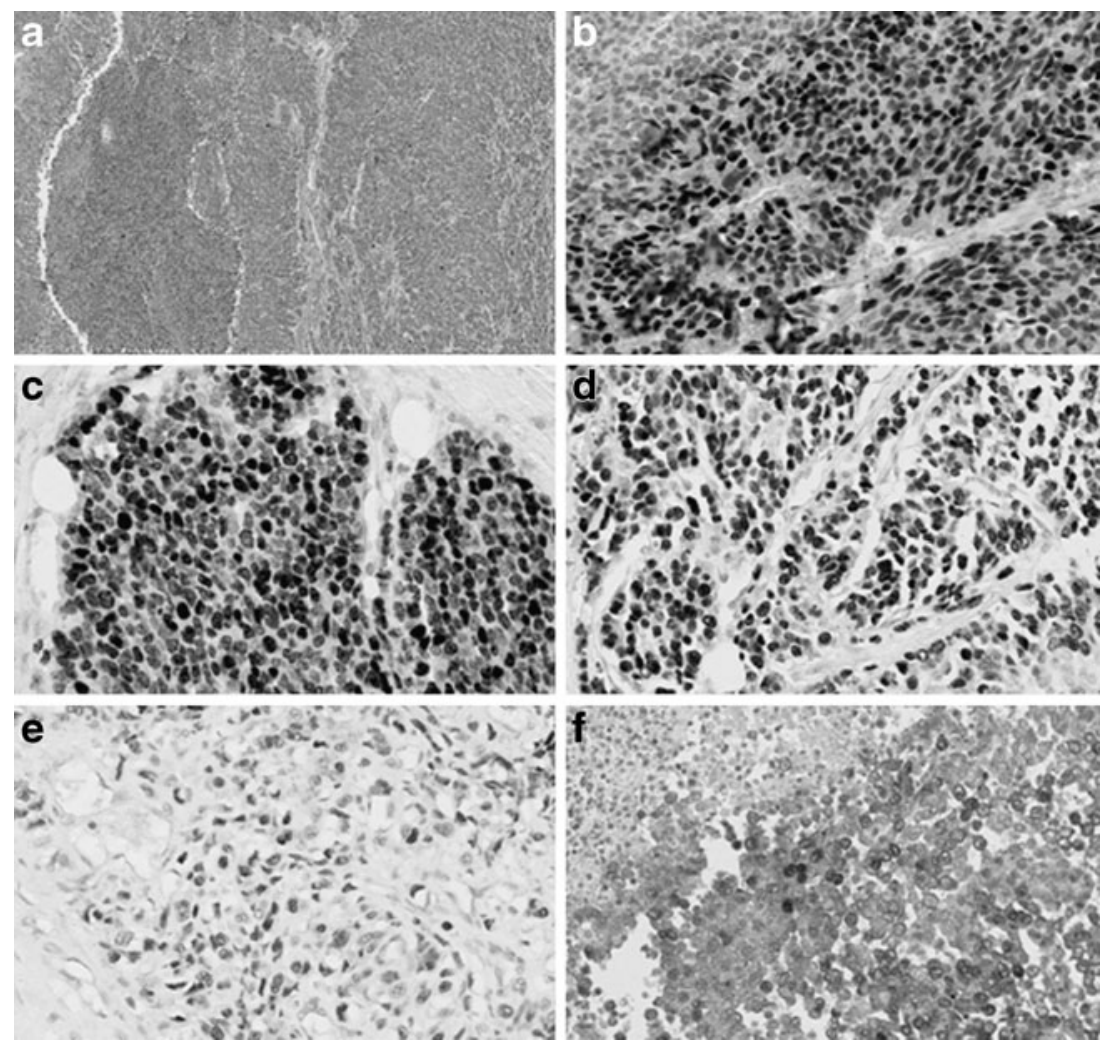
the use of MIB-1 antibody clone and the expression of the proliferation index as a percentage of positive nuclei after counting 500-2,000 cells in the areas of strongest nuclear labeling, as suggested for neuroendocrine neoplasms [6].

\section{P53}

Germline mutation of the tumor suppressor gene TP53 is responsible for the $\mathrm{Li}$-Fraumeni syndrome, a syndrome that can include ACC. Somatic TP53 mutations are found in $25-30 \%$ of sporadic ACC, but not in ACA. Positive p53 immunohistochemistry is well correlated with the presence of TP53 mutation in ACC [26]. In particular, ACC harboring TP53 mutation were associated with a more advanced stage of tumor progression and had a shorter disease-free survival [25]. More recently, these data have been confirmed by Ragazzon et al. [32], demonstrating that the $\mathrm{p} 53$ pathway is involved in the pathogenesis of ACC with poor prognosis. Immunohistochemistry study for p53 has thus a limited interest for evaluating malignancy because despite a good specificity, few ACC are positive, but it is of interest to evaluate the prognosis of ACC.

\section{IGF-II}

It can be interesting to try to evaluate insulin-like growth factor II (IGF-II) by immunohistochemistry because overexpression is observed in $90 \%$ of ACC and almost none in ACA. A few studies have been performed [36, 51]. Wilkin et al. have reported four pediatric ACC that were all positive for IGF-II [51]. Schmitt et al. have reported 22 ACA and 17 ACC; 76\% of the ACC were IGF-II positive with a dot perinuclear labeling, whereas no ACA were positive [36]. Wilkin et al. [51] used a classical method of labeling, whereas Schmitt et al. [36] revealed the labeling by intensification with cobalt ions. The difficulty to show the labeling might explain why anti-IGF-II antibody is not widely used [40].

\section{Cyclin E}

It has been shown in ACT overexpressing IGF-II gene that G1 cyclins and cyclin-dependent kinase (CDK) production, including cyclin $\mathrm{E}$ and $\mathrm{CDK} 2$, were positively regulated [7]. By immunohistochemistry, Tissier et al. showed that ACC overexpress cyclin E (5\%) contrary to ACA and that cyclin E overproduction was significantly associated with shorter disease-free survival in univariate analysis, demonstrating its adverse prognostic significance [42].

\section{$\beta$-Catenin}

Activation of the $\mathrm{Wnt} / \beta$-catenin signaling pathway is frequent in ACC, and can be associated to somatic $\beta$-catenin gene mutation [41]. This leads to $\beta$-catenin accumulation, demonstrated by immunohistochemistry [41].

Moreover, it has been demonstrated that Wnt $/ \beta$-catenin activation, confirmed by the presence of $\beta$-catenin nuclear staining, is associated with a more aggressive phenotype and is an independent prognostic factor of overall and disease-free survival in patients with resected primary ACC [18].

\section{Steroidogenic Factor-1}

In the past, SF-1 has been suggested as a marker to differentiate between tumors of adrenocortical and nonadrenocortical origin [34]. Recent studies have demonstrated overexpression of SF-1 in most cases of childhood adrenocortical tumors [11]. Moreover, Sbiera et al. [35] confirmed that SF-1 is a highly valuable immunohistochemical marker to determine the adrenocortical origin of an adrenal mass and demonstrated that SF-1 expression is of stage-independent prognostic value in patients with ACC.

\section{Conclusion}

The Weiss system is considered the mainstay in differentiating the benign and malignant adrenocortical tumors in the adult population [23, 48, 49]. Although the Weiss system is largely used in assessing malignancy in adrenocortical tumors, some limits to its use are still open. For these reasons, new tools are necessary in order to solve some important issues as: (1) the borderline cases and (2) the ACC variants. In particular, important advances are made in the physiopathology of the adrenocortical tumors thanks to genetic studies, and this allowed to identify new molecular markers useful also in the immunohistochemical diagnosis.

Acknowledgments This work was partially supported by grants from the Italian Association for Cancer Research (AIRC, Milan, grant no. IG/ 10795/2010 to MP) from the Regione Piemonte (Progetto Ricerca Sanitaria Finalizzata, D.G.R. n. 35-4231 dated 06.11.2006 to MV) and from Assistance Publique-Hôpitaux de Paris (Contrat d'Initiation à la Recherche Clinique 2005, CIRC 05045 to FT). A part of the presented research works was performed in partnership with the Department of Pathology of Cochin Hospital of Pr Marie-Cécile Vacher-Lavenu (Hôpital Cochin, AP-HP, Faculté de Médecine Paris Descartes, Université Paris Descartes), the Department of Endocrinology of Pr Xavier Bertagna (Hôpital Cochin, AH-HP, Faculté de Médecine Paris Descartes, Université Paris Descartes) et Team 10 of the Department "Endocrinologie Métabolisme Cancer" of Pr Jérôme Bertherat (Unité INSERM U567CNRS UMR8104, Institut Cochin, Paris) in the French network of endocrine tumors COMETE.

Conflict of Interest All Authors declare the absence of any conflict of interest. 


\section{References}

1. Assie G, Antoni G, Tissier F, Caillou B, Abiven G, Gicquel C, Leboulleux $S$ et al (2007) Prognostic parameters of metastatic adrenocortical carcinoma. J Clin Endocrinol Metab 92(1):148-154

2. Aubert S, Wacrenier A, Leroy X, Devos P, Carnaille B, Proye C, Wemeau JL, Lecomte-Houcke M, Leteurtre E (2002) Weiss system revisited: a clinicopathologic and immunohistochemical study of 49 adrenocortical tumors. Am J Surg Pathol 26 (12):1612-1619

3. Barksdale SK, Marincola FM, Jaffe G (1993) Carcinosarcoma of the adrenal cortex presenting with mineralocorticoid excess. Am J Surg Pathol 17(9):941-945

4. Bisceglia M, Ludovico O, Di Mattia A, Ben-Dor D, Sandbank J, Pasquinelli G, Lau SK, Weiss LM (2004) Adrenocortical oncocytic tumors: report of 10 cases and review of the literature. Int J Surg Pathol 12(3):231-243

5. Blanes A, Diaz-Cano SJ (2007) Histologic criteria for adrenocortical proliferative lesions: value of mitotic figure variability. Am J Clin Pathol 127(3):398-408

6. Rindi G, Arnold R, Bosman FT, Capella C, Klimstra DS, Kloppel G, Komminoth P, Solcia E (2010) Nomenclature and classification of neuroendocrine neoplasms of the digestive system. In: Bosman FT, Carneiro F, Hruban RH, Theise ND (eds) Tumors of the Digestive System. World Health Organization Classification of Tumours. Pathology and Genetics. IARC Press, Lyon, pp 13-14

7. Bourcigaux N, Gaston V, Logie A, Bertagna X, Le Bouc Y, Gicquel C (2000) High expression of cyclin E and G1 CDK and loss of function of p57KIP2 are involved in proliferation of malignant sporadic adrenocortical tumors. J Clin Endocrinol Metab 85(1):322-330

8. Coli A, Di Giorgio A, Castri F, Destito C, Marin AW, Bigotti G (2010) Sarcomatoid carcinoma of the adrenal gland: a case report and review of literature. Pathol Res Pract 206(1):59-65

9. Collina G, Maldarizzi F, Betts CM, Eusebi V (1989) Primary sarcomatoid carcinoma of the adrenal gland. First case report. Virchows Arch A Pathol Anat Histopathol 415(2):161-167

10. Decorato JW, Gruber H, Petti M, Levowitz BS (1990) Adrenal carcinosarcoma. J Surg Oncol 45(2):134-136

11. El Wakil A, Doghman M, Latre De Late P, Zambetti GP, Figueiredo BC, Lalli E (2011) Genetics and genomics of childhood adrenocortical tumors. Mol Cell Endocrinol 336(12):169-173

12. Fassnacht M, Allolio B (2009) Clinical management of adrenocortical carcinoma. Best Pract Res Clin Endocrinol Metab 23 (2):273-289

13. Fassnacht M, Johanssen S, Quinkler M, Bucsky P, Willenberg HS, Beuschlein F, Terzolo M, Mueller HH, Hahner S, Allolio B, German Adrenocortical Carcinoma Registry Group, European Network for the Study of Adrenal Tumors (2009) Limited prognostic value of the 2004 International Union Against Cancer staging classification for adrenocortical carcinoma: proposal for a Revised TNM Classification. Cancer 115(2):243-250

14. Fassnacht M, Libe R, Kroiss M, Allolio B, Medscape (2011) Adrenocortical carcinoma: a clinician's update. Nat Rev Endocrinol 7(6):323-335

15. Fenske W, Volker HU, Adam P, Hahner S, Johanssen S, Wortmann S, Schmidt M et al (2009) Glucose transporter GLUT1 expression is an stage-independent predictor of clinical outcome in adrenocortical carcinoma. Endocr Relat Cancer 16(3):919-928

16. Fischler DF, Nunez C, Levin HS, McMahon JT, Sheeler LR, Adelstein DJ (1992) Adrenal carcinosarcoma presenting in a woman with clinical signs of virilization. A case report with immunohistochemical and ultrastructural findings. Am J Surg Pathol 16(6):626-631
17. Fuhrman SA, Lasky LC, Limas C (1982) Prognostic significance of morphologic parameters in renal cell carcinoma. Am J Surg Pathol 6(7):655-663

18. Gaujoux S, Grabar S, Fassnacht M, Ragazzon B, Launay P, Libe $\mathrm{R}$, Chokri I et al (2011) Beta-catenin activation is associated with specific clinical and pathologic characteristics and a poor outcome in adrenocortical carcinoma. Clin Cancer Res 17(2):328-336

19. Giordano TJ (2011) The argument for mitotic rate-based grading for the prognostication of adrenocortical carcinoma. Am J Surg Pathol 35(4):471-473

20. Giordano TJ, Kuick R, Else T, Gauger PG, Vinco M, Bauersfeld J, Sanders D, Thomas DG, Doherty G, Hammer G (2009) Molecular classification and prognostication of adrenocortical tumors by transcriptome profiling. Clin Cancer Res 15(2):668-676

21. Hough AJ, Hollifield JW, Page DL, Hartmann WH (1979) Prognostic factors in adrenal cortical tumors. A mathematical analysis of clinical and morphologic data. Am J Clin Pathol 72 (3):390-399

22. Lack E (2007) Adrenal cortical carcinoma. Tumours of the adrenal gland and paraganglia. In: Silverberg S (ed) AFIP atlas of tumor pathology, series 4. Armed Forces Institute of Pathology, Washington, DC, pp 131-155

23. Lau SK, Weiss LM (2009) The Weiss system for evaluating adrenocortical neoplasms: 25 years later. Hum Pathol 40(6):757768

24. Lee MS, Park IA, Chi JG, Ham EK, Lee KC, Lee CW (1997) Adrenal carcinosarcoma-a case report. J Korean Med Sci 12 (4):374-377

25. Libe R, Fratticci A, Bertherat J (2007) Adrenocortical cancer: pathophysiology and clinical management. Endocr Relat Cancer 14(1):13-28

26. Libe R, Groussin L, Tissier F, Elie C, Rene-Corail F, Fratticci A, Jullian E et al (2007) Somatic TP53 mutations are relatively rare among adrenocortical cancers with the frequent $17 \mathrm{p} 13$ loss of heterozygosity. Clin Cancer Res 13(3):844-850

27. McNicol AM (2008) Lesions of the adrenal cortex. Arch Pathol Lab Med 132(8):1263-1271

28. Miller BS, Gauger PG, Hammer GD, Giordano TJ, Doherty GM (2010) Proposal for modification of the ENSAT staging system for adrenocortical carcinoma using tumor grade. Langenbecks Arch Surg 395(7):955-961

29. Morimoto R, Satoh F, Murakami O, Suzuki T, Abe T, Tanemoto $\mathrm{M}$, Abe $\mathrm{M}$ et al (2008) Immunohistochemistry of a proliferation marker Ki67/MIB1 in adrenocortical carcinomas: Ki67/MIB1 labeling index is a predictor for recurrence of adrenocortical carcinomas. Endocr J 55(1):49-55

30. Okazumi S, Asano T, Ryu M, Nagashima T, Odaka M, Isono K, Nishizawa T (1987) Surgical resection of adrenal carcinoma extending into the vena cava, right atrium and ventricle: case report and review of the literature. Nippon Geka Gakkai Zasshi 88 (2):231-238

31. Papotti M, Volante M, Duregon E, Delsedime L, Terzolo M, Berruti A, Rosai J (2010) Adrenocortical tumors with myxoid features: a distinct morphologic and phenotypical variant exhibiting malignant behavior. Am J Surg Pathol 34(7):973-983

32. Ragazzon B, Libe R, Gaujoux S, Assie G, Fratticci A, Launay P, Clauser E et al (2010) Transcriptome analysis reveals that p53 and \{beta\}-catenin alterations occur in a group of aggressive adrenocortical cancers. Cancer Res 70(21):8276-8281

33. Sasaki K, Desimone M, Rao HR, Huang GJ, Seethala RR (2010) Adrenocortical carcinosarcoma: a case report and review of the literature. Diagn Pathol 5:51

34. Sasano H, Shizawa S, Suzuki T, Takayama K, Fukaya T, Morohashi K, Nagura H (1995) Transcription factor adrenal 4 binding protein as a marker of adrenocortical malignancy. Hum Pathol 26(10):1154-1156 
35. Sbiera S, Schmull S, Assie G, Voelker HU, Kraus L, Beyer M, Ragazzon B et al (2010) High diagnostic and prognostic value of steroidogenic factor- 1 expression in adrenal tumors. J Clin Endocrinol Metab 95(10):E161-E171

36. Schmitt A, Saremaslani P, Schmid S, Rousson V, Montani M, Schmid DM, Heitz PU, Komminoth P, Perren A (2006) IGFII and MIB1 immunohistochemistry is helpful for the differentiation of benign from malignant adrenocortical tumours. Histopathology 49 (3):298-307

37. Stojadinovic A, Brennan MF, Hoos A, Omeroglu A, Leung DH, Dudas ME, Nissan A, Cordon-Cardo C, Ghossein RA (2003) Adrenocortical adenoma and carcinoma: histopathological and molecular comparative analysis. Mod Pathol 16(8):742-751

38. Sturm N, Moulai N, Laverriere MH, Chabre O, Descotes JL, Brambilla E (2008) Primary adrenocortical sarcomatoid carcinoma: case report and review of literature. Virchows Arch 452 (2):215-219

39. Terzolo M, Boccuzzi A, Bovio S, Cappia S, De Giuli P, Ali A, Paccotti P, Porpiglia F, Fontana D, Angeli A (2001) Immunohistochemical assessment of Ki-67 in the differential diagnosis of adrenocortical tumors. Urology 57(1):176-182

40. Tissier F (2010) Classification of adrenal cortical tumors: what limits for the pathological approach? Best Pract Res Clin Endocrinol Metab 24(6):877-885

41. Tissier F, Cavard C, Groussin L, Perlemoine K, Fumey G, Hagnere AM, Rene-Corail F et al (2005) Mutations of betacatenin in adrenocortical tumors: activation of the Wnt signaling pathway is a frequent event in both benign and malignant adrenocortical tumors. Cancer Res 65(17):7622-7627

42. Tissier F, Louvel A, Grabar S, Hagnere AM, Bertherat J, VacherLavenu MC, Dousset B, Chapuis Y, Bertagna X, Gicquel C (2004) Cyclin E correlates with malignancy and adverse prognosis in adrenocortical tumors. Eur J Endocrinol 150(6):809-817

43. van Slooten H, Schaberg A, Smeenk D, Moolenaar AJ (1985) Morphologic characteristics of benign and malignant adrenocortical tumors. Cancer 55(4):766-773
44. van't Sant HP, Bouvy ND, Kazemier G, Bonjer HJ, Hop WC, Feelders RA, de Herder WW, de Krijger RR (2007) The prognostic value of two different histopathological scoring systems for adrenocortical carcinomas. Histopathology 51 (2):239-245

45. Volante M, Bollito E, Sperone P, Tavaglione V, Daffara F, Porpiglia F, Terzolo M, Berruti A, Papotti M (2009) Clinicopathological study of a series of 92 adrenocortical carcinomas: from a proposal of simplified diagnostic algorithm to prognostic stratification. Histopathology 55(5):535-543

46. Volante M, Buttigliero C, Greco E, Berruti A, Papotti M (2008) Pathological and molecular features of adrenocortical carcinoma: an update. J Clin Pathol 61(7):787-793

47. Volante M, Sperone P, Bollito E, Frangipane E, Rosas R, Daffara F, Terzolo M, Berruti A, Papotti M (2006) Matrix metalloproteinase type 2 expression in malignant adrenocortical tumors: diagnostic and prognostic significance in a series of 50 adrenocortical carcinomas. Mod Pathol 19(12):1563-1569

48. Weiss LM (1984) Comparative histologic study of 43 metastasizing and nonmetastasizing adrenocortical tumors. Am J Surg Pathol 8 (3):163-169

49. Weiss LM, Medeiros LJ, Vickery AL Jr (1989) Pathologic features of prognostic significance in adrenocortical carcinoma. Am J Surg Pathol 13(3):202-206

50. Wieneke JA, Thompson LD, Heffess CS (2003) Adrenal cortical neoplasms in the pediatric population: a clinicopathologic and immunophenotypic analysis of 83 patients. Am J Surg Pathol 27 (7):867-881

51. Wilkin F, Gagne N, Paquette J, Oligny LL, Deal C (2000) Pediatric adrenocortical tumors: molecular events leading to insulin-like growth factor II gene overexpression. J Clin Endocrinol Metab 85(5):2048-2056

52. Wong DD, Spagnolo DV, Bisceglia M, Havlat M, McCallum D, Platten MA (2011) Oncocytic adrenocortical neoplasms-a clinicopathologic study of 13 new cases emphasizing the importance of their recognition. Hum Pathol 42(4):489-499 